\title{
GENERALIZED PERITONITIS WITH UTERINE INCISION NECROSIS WITH DEHISCENCE FOLLOWING CESAREAN SECTION PRESENTING AS GENITOURINARY FISTULA: A UNIQUE COMPLICATION
}

Madhuri Alwani ${ }^{1}$,Sunita Mishra ${ }^{2}$, Ratna Thakur ${ }^{3}$

HOW TO CITE THIS ARTICLE:

Madhuri Alwani, Sunita Mishra, Ratna Thakur. "Generalized Peritonitis with Uterine Incision Necrosis with Dehiscence following Cesarean Section presetting as Genitourinary Fistula: A Unique Complication". Journal of Evolution of Medical and Dental Sciences 2014; Vol. 3, Issue 03, January 20; Page: 762-766,

DOI: $10.14260 /$ jemds/2014/1899

ABSTRACT: Generalized peritonitis following lower segment caesarean section with uterine incision necrosis and dehiscence presenting as genitourinary fistula is very unusual. Herein we report a case of 28 years old woman who was received in emergency hours as a referred case from a private nursing home with history of caesarean section done 11 days back for premature rupture of membranes and pregnancy induced hypertension. She came with complaints of continuous watery discharge per vaginum, high grade fever with chills and rigor, nausea, vomiting, breathlessness, severe diffuse abdominal pain and distension of abdomen since last 4-5 days. Here acute abdomen series was done. The urologist ruled out genitourinary fistula. CECT of abdomen was done. She was diagnosed to be a case of generalized peritonitis following caesarean section with necrosis and dehiscence of suture line of uterus through which ascitic fluid was being drained into vagina. Consequently, patient underwent laparotomy. Gentle adhesiolysis with supra cervical hysterectomy was done. Thorough drainage and irrigation of pelvi-abdominal cavity was done. Post-operative period was uneventful.

INTRODUCTION: It is unusual for peritonitis to develop following caesarean delivery. It is almost invariably preceded by metritis and uterine incisional necrosis and dehiscence. Other cases may be due to inadvertent bowel injury at caesarean delivery. Yet another cause is peritonitis following rupture of a parametrial or adnexal abscess. ${ }^{1}$ Herein we report a case of 28 years old woman who was received in emergency hours as a case of post-operative caesarean section which was done in a private nursing home 11 days back. She presented with complaints of continuous watery discharge per vaginum, high grade fever with chills and rigor, nausea, vomiting, breathlessness, severe diffuse abdominal pain and distension of abdomen since last 6-7 days. The first clinical impression that she gave was that of a genitourinary fistula following caesarean section. After complete work up, her provisional diagnosis was to be a case of generalized peritonitis following post caesarean uterine wound necrosis with dehiscence and the ascitic fluid was being drained through this uterine rent. Emergency laparotomy was done. Gentle adhesiolysis with supracervical hysterectomy was done. Post-operative period was uneventful.

CASE REPORT: A 27 years old female patient was received in emergency department with complaints of high grade fever with chills and rigors, breathlessness, diffuse pain and distension of abdomen and watery discharge per vaginum since 4-5 days. She had undergone cesarean section in a private nursing home 11 days back. The indication of LSCS was transverse lie with premature rupture of membranes with Pregnancy induced hypertension. On $11^{\text {th }}$ post op day she was brought 
to our institute with the above mentioned complaints. She had not passed motion since last 3 days. She was voiding urine normally along with continuous watery discharge per vaginum. She was a multiparous woman with three full term normal vaginal deliveries and they were all alive \& healthy. This was her $4^{\text {th }}$ pregnancy and delivered by cesarean section. Past medical and surgical history was uneventful.

On physical examination, she looked ill and in pain. Her vitals were as follows: temperature $38.7^{\circ} \mathrm{C}$, blood pressure $104 / 70 \mathrm{mmHg}$, heart rate (pulse) of $120 / \mathrm{min}$, respiratory rate 32 breaths /min and oxygen saturation of $94 \%$ at room air. There was diminished air entry in both lungs. Bilateral crepitations were present. Distension of abdomen was present. Fluid thrill and shifting dullness were present. Bowel sounds were sluggish. Transverse scar was present over lower abdomen. Dressing was dry. On Per speculum examination: Vagina was full of watery discharge with flakes of pus coming through cervix. On bimanual P/V examination: Os was closed and exact size of uterus could not be made out because of distension of abdomen.

Initial laboratory results showed leukocytosis of more than $26000 / \mathrm{mm}^{3}$ (high neutrophilia), $\mathrm{Hb} 8.0 \mathrm{gm} . \%$, lactic acid of $2.1 \mathrm{mmol} / \mathrm{L}$, serum bilirubin $2.68 \mathrm{mg} \%$, coagulation profile marginally deranged and normal renal function test. An urgent bed side USG whole abdomen was done. Report showed gross ascites with bulky uterus. Urologist opinion was taken to rule out post-operative genitourinary fistula. There was no leakage of urine on retrograde filling of the bladder. Ascitic tap was done to rule out urinary ascites. Acute abdomen series was done and a plain chest radiograph (X-ray) was done. That showed bilateral pleural effusion which was reactionary in nature. CECT whole abdomen and pelvis showed gross ascites with disruption of uterine cesarean incision through which the ascetic fluid was being drained out through vagina.

A provisional diagnosis of generalized peritonitis with uterine incision necrosis and dehiscence secondary to cesarean section was established. Subsequently patient underwent urgent exploratory laparotomy.

Exploratory Laparotomy was Under G/A, the abdomen was opened by right paramedian incision with all aseptic and antiseptic precautions. Abdominal cavity was full of turbid fluid with white flakes of pus. All abdominal viscera were bathed in pus. There were flimsy adhesions of all abdominal viscera. There was a complete disruption of suture line of Caesarean section on lower uterine segment. Bladder was normal. Ascitic fluid was sent for cytology and microbiology examination. Consequently, the patient underwent supracervical hysterectomy A thorough lavage of peritoneal cavity was done. A gentle adhesiolysis was done. Pus was sucked from all the cracks and crevices. Two wide bore tubal drains were put in both the flanks. After complete hemostasis abdomen was closed. And she was shifted to GICU.

Post operatively patient was admitted to intensive care unit and administered broad spectrum antibiotics. She had an uneventful recovery afterwards and was finally discharged from the hospital on $16^{\text {th }}$ day in a good physical health.

DISCUSSION: Dehiscence of a lower uterine segment incision is rare but potentially dangerous cause of generalized peritonitis. If the infection begins in an intact uterus and extends into the peritoneum, antimicrobial treatment alone usually suffices. Conversely, peritonitis caused by uterine incisional necrosis or bowel perforation must be dealt surgically.2. The incidence of peripartum hysterectomy due to post-operative uterine wound sepsis and necrosis is about $6 \%$. ${ }^{3}$.Severe cellulitis of uterine 
incision may lead to necrosis and separation. Extrusion of purulent material commonly leads to peritonitis. Because puerperal metritis with cellulitis is typically a retroperitoneal infection, evidence of peritonitis suggests the possibility of uterine incisional necrosis, or less commonly a bowel injury2. Administration of intravenous broad spectrum antibiotics within one hour of suspicion of severe sepsis, with or without septic shock is recommended ${ }^{4}$.Peritonitis is defined as inflammation of serosal membrane that lines the abdominal cavity and the organs contained therein. Intra-abdominal sepsis is a term used for intra-abdominal infections and encompasses both localized and generalized peritonitis. ${ }^{5}$ Abdominal free fluid, bowel distension, pleural effusion and bladder flap hematoma on CT in post caesarean context suggests the possibility of uterine incision necrosis/ dehiscence ${ }^{6}$.Uterine incisional dehiscence is sometimes supported by CT scanning images. These must be interpreted within the clinical context because apparent uterine incisional defects thought to represent edema can be seen even on images after uncomplicated caesarean deliveries. ${ }^{7}$

CONCLUSION: Generalized peritonitis after caesarean due to dehiscence of lower uterine segment incision with drainage of peritoneal fluid is extremely rare. Any woman with infection following caesarean delivery who is suspected of having peritonitis should be carefully evaluated for uterine incisional necrosis or bowel perforation. Uterine incision dehiscence with peritonitis may present with watery discharge per vaginum that mimics genitourinary fistula. It is to be ruled out. Prompt surgical exploration and frequently supra cervical hysterectomy may be necessary. An abdominopelvic CT scan is useful to characterize these infections.

\section{REFERENCES:}

1. Williams Obstetrics, F. Cunningham, Kenneth Leveno, Steven Bloom, John Hauth, Dwight Rouse, Catherine Spong, twenty third edition, page no. 665

2. Williams Obstetrics, F. Cunningham, Kenneth Leveno, Steven Bloom, John Hauth, Dwight Rouse, Catherine Spong, twenty third edition, page no. 666

3. R. A Kwame-Aryee. AKK wakye and J D Stefan. Peripartum hysterectomies at Korte Bu teaching hospital, Ghana medical J, 2007 September 41(3) 133-138.

4. Sepsis following pregnancy, bacterial, Royal College of obstetrician and gynecologists, April, 2012.

5. Pavlidis TE. Cellular changes in association with defense mechanism in intra-abdominal sepsis. Minerva chir, Dec 2003; 58(6); 777-81 (med line).

6. Rivlin ME, Patel RB, Caroll CS, Morrison JC. Diagnostic imaging in uterine incisional necrosis/dehiscence complicating cesarean section.J Reprod.med.2005, and Dec: 50 (12): 928-32.

7. Twikler DM, Setiawan AT, Harrel RS et al. CT appearance of pelvis after caesarean section. IS J Roengen; 156:523, 199. 


\section{CASE REPORT}

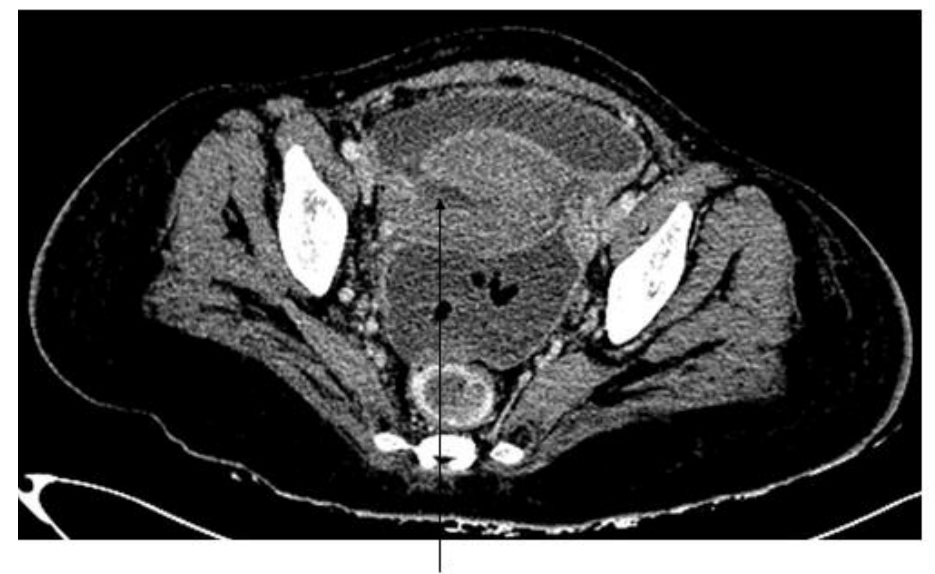

Fig. 1: CT Scan showing Uterine wound disruption

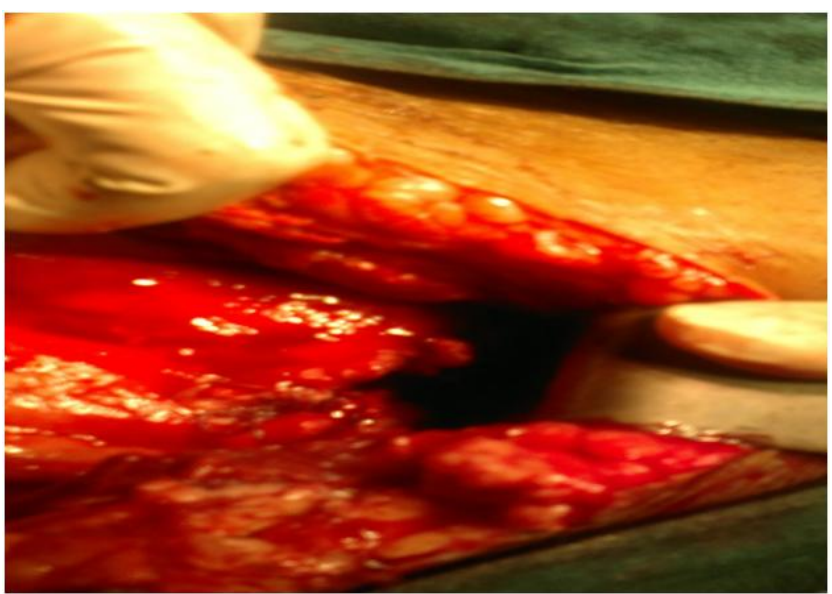

Fig. 2: Picture showing dehiscence of uterine incision

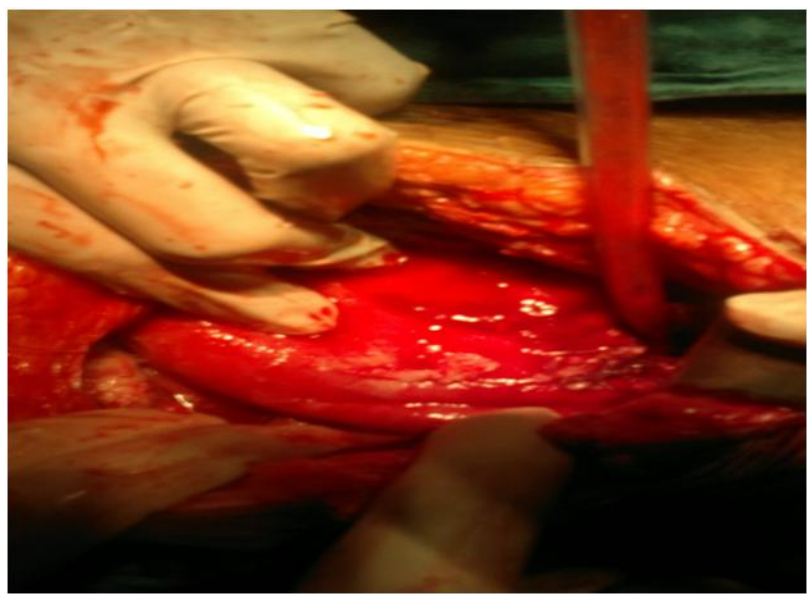

Fig. 3: Picture showing disruption of caesarean scar 


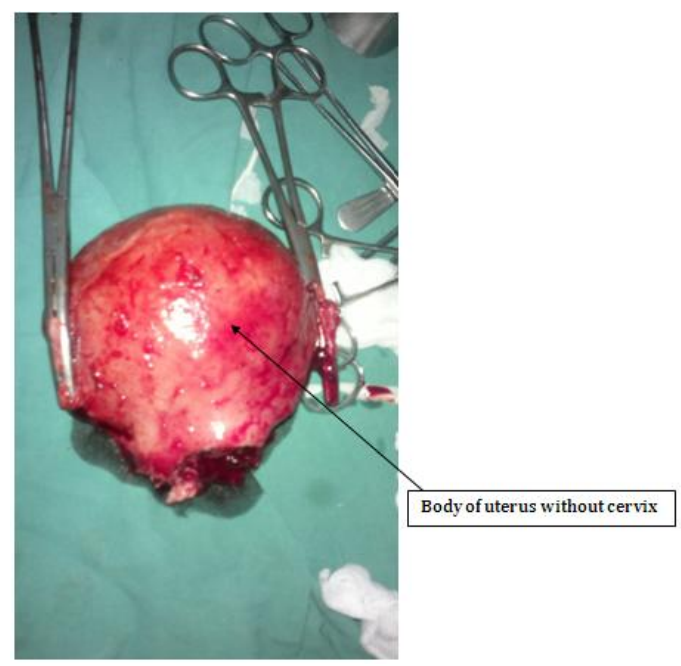

Fig. 4: Supra cervical hysterectomy

\section{AUTHORS:}

1. Madhuri Alwani

2. Sunita Mishra

3. Ratna Thakur

\section{PARTICULARS OF CONTRIBUTORS:}

1. Assistant Professor, Department of Obstetrics and Gynaecology, Sri Aurobindo Institute of Medical Sciences \& P.G. Institute, Indore.

2. Senior Resident, Department of Obstetrics and Gynaecology, Sri Aurobindo Institute of Medical Sciences \& P.G. Institute, Indore.

3. Professor \& HOD, Department of Obstetrics and Gynaecology, Sri Aurobindo Institute of Medical Sciences \& P.G. Institute, Indore.

\section{NAME ADDRESS EMAIL ID OF THE CORRESPONDING AUTHOR:}

Dr.Madhuri Alwani,

Shalimar Malwa Enclave,

H. No. 1/201, Opp. C-21 Mall,

Near Lotus show room,

AB Road, Indore.

Email -drmadhuri_2007@rediffmail.com

Date of Submission:03/01/2014. Date of Peer Review: 04/01/2014.

Date of Acceptance: 09/01/2014.

Date of Publishing: 18/01/2014. 